\title{
Intervention thresholds for osteoporosis in men and women: a study based on data from Sweden
}

\author{
John A. Kanis · Olof Johnell \\ Anders Oden · Frederik Borgstrom \\ Helena Johansson · Chris De Laet · Bengt Jönsson
}

Received: 15 October 2003/ Accepted: 1 March 2004/Published online: 22 April 2004

(C) International Osteoporosis Foundation and National Osteoporosis Foundation 2004

\begin{abstract}
The aim of this study was to determine the threshold of fracture probability at which interventions became cost-effective in men and women, based on data from Sweden. We modeled the effects of a treatment costing \$500 per year given for 5 years that decreased the risk of all osteoporotic fractures by $35 \%$ followed by a waning of effect for a further 5 years. Sensitivity analyses included a range of effectiveness $(10-50 \%)$ and a range of intervention costs (\$200-500/year). Data on costs and risks were from Sweden. Costs included direct costs, but excluded indirect costs due to morbidity. A threshold for cost-effectiveness of approximately $\$ 45,000 /$ QALY gained was used. Cost of added years was included in a sensitivity analysis. With the base case (\$500 per year; 35\% efficacy) treatment in women was cost-effective with a 10 -year hip fracture probability that ranged from $1.2 \%$ at the age of 50 years to $7.4 \%$ at the age of 80 years. Similar results were observed in men except that the threshold for cost-effectiveness was higher at younger ages than in women ( 2.0 vs $1.2 \%$, respectively, at the age of 50 years). Intervention
\end{abstract}

\section{J. A. Kanis ( $\square)$ \\ Centre for Metabolic Bone Diseases \\ (WHO Collaborating Centre), \\ University of Sheffield Medical School, \\ Beech Hill Road, Sheffield, S10 2RX, UK \\ E-mail: w.j.Pontefract@shef.ac.uk \\ Fax: + 44-114-2851318 \\ O. Johnell \\ Department of Orthopaedics, \\ Malmo General Hospital, Malmo, Sweden}

A. Oden $\cdot$ H. Johansson

Consulting Statistician, Solberg 8414,

44292 Romelanda, Sweden

F. Borgstrom · B. Jönsson

Stockholm Health Economics, Stockholm, Sweden

C. De Laet

Department of Public Health, Erasmus Medical Center,

Rotterdam, The Netherlands thresholds were sensitive to the assumed effectiveness and intervention cost. The exclusion of osteoporotic fractures other than hip fracture significantly increased the cost-effectiveness ratio because of the substantial morbidity from such other fractures, particularly at younger ages. We conclude that the inclusion of all osteoporotic fractures has a marked effect on intervention thresholds, that these vary with age, and that available treatments can be targeted cost-effectively to individuals at moderately increased fracture risk.

Keywords Cost-effectiveness - Cost of added years . Hip fracture $\cdot$ Intervention threshold $\cdot$ Osteoporotic fracture

\section{Introduction}

There is a growing opinion that intervention thresholds for osteoporosis should be based on absolute risk (probability) of fracture rather than solely on diagnostic thresholds provided by the $T$-score of bone mineral density (BMD) $[1,2]$. A similar approach is used in cardiovascular disease where absolute risk has been used to determine intervention thresholds for primary prevention with lipid lowering agents $[3,4,5,6,7]$.

The setting of intervention thresholds in osteoporosis should take account of the multiple outcomes of osteoporosis-namely the different fracture outcomes and their associated morbidity. We have previously characterized the morbidity that arises from osteoporotic fractures so that the fracture risk can be weighted according to the morbidity occasioned by each osteoporotic fracture [8]. The technique reduces fracture risk to a common currency rather than considering the multiple outcomes that complicate risk assessment. In addition, the weightings are based on utilities lost (disutility), so that they can be used for health economic assessment. This and other approaches have been used to characterize intervention thresholds of fracture risk in 
women that can be justified from a cost-effectiveness perspective $[9,10]$.

Since then, recent studies in patients have suggested that the morbidity arising from vertebral fractures is very significant, and far greater than hitherto appreciated based on expert opinion [11, 12, 13, 14, 15, 16]. Indeed, the loss of quality of life in the 1st year after fracture may be of the same order of magnitude as that for hip fracture $[13,17]$. In addition, there is now more epidemiological information available in men. Such data suggest that fracture risk for any given BMD (at the hip or spine) is similar in men and women [18, 19, 20, 21], and that additional risk factors such as prior fracture, corticosteroid use, and low body mass index have a similar significance in men as they have in women [21, $22,23]$. The objectives of this paper were to update thresholds of risk at which intervention could be considered cost-effective in women and additionally to provide intervention thresholds for men, modeled on the population of Sweden. For this purpose we chose a health service perspective, based on direct costs, but a societal perspective was examined in a sensitivity analysis.

\section{Methods}

The model used was based on a Markov model using data on fracture risk derived from the population of Sweden [24, 25]. Direct costs were defined as intervention costs, including those from diagnosis, drugs, and monitoring of treatment minus the savings from a reduction in the future number of osteoporotic fractures needed to be treated. Indirect costs were not included in this analysis. Costs, using values for the years 20002001, were derived in SEK but were converted to US\$ at a conversion rate for the year $2001(\$ 1=9.53$ SEK $)$. Fracture costs were estimated as the difference between the cost during the years after fracture and the costs in the year preceding the fracture. The costs of hip fracture in the 1st year rose from $\$ 8,636$ for those patients between the ages of 50 and 64 years, to $\$ 23,200$ at the age of 85 years or more [26]. Additional costs in the 2nd and subsequent years were assumed to be constant $(\$ 4,785)$. Since costings for all types of osteoporotic fractures and age weights were not available, the costs of other osteoporotic fractures were assumed to be proportional to the disutility incurred by these fractures compared with that of hip fracture [8]. A recent cost analysis in Rochester indicated that the total incremental costs of all fractures other than those at the hip were 47 and $46 \%$ higher than the costs of hip fractures in men and women, respectively. The morbidity of nonhip osteoporotic fractures was 39 and $47 \%$ higher than for hip fracture in men and women, respectively, suggesting the appropriateness of this assumption [27, 28].

In a sensitivity analysis we examined the effects of intervention on clinical vertebral fracture without effects on hip fracture. The cost of a clinical vertebral fracture was taken as $\$ 3,200$, based on empirical data from Malmo [13] and similar to incremental costs calculated for the United States [29].

The avoidance of fracture was assumed to reduce associated deaths only in the 1st year after fracture. Thus, a minority of fracture-associated mortality was assumed to be prevented in accordance with empirical and epidemiological data [30, 31]. Costs from increased survival were excluded in the base-case analysis in order to facilitate comparisons with other published estimates of cost-effectiveness in osteoporosis. These costs were included in a sensitivity analysis. A threshold value of $\$ 45,000$ per QALY gained compared to no treatment was taken as an indication of cost-effectiveness using direct costs in line with the recommendations of the National Institute for Clinical Excellence, United Kingdom (NICE) [32]. This is somewhat higher than that proposed by the NOF in 1998 [9] and previously used by ourselves [10, 25]. A threshold of $\$ 64,000 /$ QALY gained was used in sensitivity analyses where cost of added years was included [7]. The higher bench-mark value is commonly used when costs in added years of life are included [7, 33].

An intervention of 5 years was assumed, targeted to the male or female population at a given 10-year hip fracture probability at any given age. The hip fracture probability varied from 0.5 to $8 \%$. The 5 -year treatment was chosen to approximate the time period for which there are direct or indirect clinical data on intervention effects. After stopping intervention, the risk reduction was assumed to reverse in a linear manner over a 5-year period $[25,34]$. We used a relative risk reduction (RRR) of $35 \%$ for all osteoporotic fractures from the onset of treatment as the base case, which approximates the effect of hormone replacement treatment on all fractures [35] and vitamin $\mathrm{D}$ with calcium on hip fracture risk [36]. We additionally examined an effectiveness of $20 \%$ and $50 \%$. The latter approximates the average risk reduction from clinical trials with the bisphosphonates [37, 38, 39, 40, 41] and from observational evidence with the recent use of estrogens [42, 43, 44]. The former accommodates an imperfect compliance, at least with regard to efficacy. Finally, we modeled an efficacy of $10 \%$, since even treatments with low efficacy but low costs may still be targeted cost-effectively [45].

Four different intervention cost levels of $\$ 200, \$ 300$, $\$ 400$, and $\$ 500$ per annum were investigated. The highest cost was used for the base case. The two higher costs approximate the cost in Sweden of transdermal hormone replacement treatment and bisphosphonate intervention, respectively, together with the costs of monitoring for a yearly hospital visit and a BMD test every 2 years. The lower costs encompass cheaper forms of hormone replacement therapy and calcium with and without vitamin $\mathrm{D}$, and vitamin $\mathrm{D}$ alone. For the calculation of intervention thresholds, the base-case treatment (35\% efficacy $/ \$ 500$ p.a.) was directed at the male and female population over a range of fracture probabilities and age, and the probability of hip fracture 
computed at which costs crossed the threshold for costeffectiveness. All simulations were undertaken using a discount rate of 3\% for both costs and benefits (QALY).

For hip fracture rates we used national data from Stockholm 1990 [46]. For vertebral fractures (those coming to clinical attention), proximal humerus, and Colles fracture, we used data from Malmo [47]. For other osteoporotic fractures (distal femur, proximal tibia, ribs, sternum, scapula, pelvis, shaft of humerus, and clavicle), we used rates calculated for Sweden (19911997) [47]. Tibial fractures in men were not considered to be due to osteoporosis [8]. Age-specific fracture rates and mortality were assumed not to change over the lifetime of individuals. The assumption on mortality underestimates lifetime risk [48], but has little impact over the intervention period.

Utility loss following a fracture was assumed to be similar in men and women. For hip fracture a multiplier of 0.79 was applied to health state values for age to compute loss of QALYs in the 1st year and 0.9 in subsequent years [25]. The utility loss for all other fractures was derived from estimates of the National Osteoporosis Foundation [9] with minor modifications [17]. For the purposes of modeling, excess morbidity from all other fractures was computed as a ratio of that due to hip fracture at any given age [8]. Excess morbidity was 6.1 in women between the ages of 50 and 55 years - i.e., the morbidity (and costs) associated with other osteoporotic fractures was 6.1 times than that accounted for by hip fractures alone. For men this was 4.5 at the same ages. Excess morbidity decreased with age to approximately 1.5 from the ages of 80 years onwards [17].

When a person had a fracture, subsequent costs for intervention as well as further fractures were assumed to be zero. We estimated, therefore, the cost-effectiveness of preventing only the first fracture since, if it were costeffective to prevent the first fracture, it would probably also be cost-effective to prevent the second, due to the higher risk in the population with a previous fracture [49]. When an individual had a fracture, all future costs related to that fracture were included in the cost per fracture for the 1st year [50]. Excess mortality after fracture was included for the 1st year after fracture [25] and assumed to be the same as the general population for the 2nd and subsequent years.

\section{Results}

The cost-effectiveness of the base-case treatment (\$500) and of midrange efficacy ( $35 \%$ effectiveness) is shown in Fig. 1 at different ages and different hip fracture probabilities. As expected, cost-effectiveness improved at any age with increasing fracture probability, due to the higher risk of fracture and thus the greater number of fractures avoided. For any given hip fracture probability, cost-effectiveness improved with decreasing age since more nonhip fractures were avoided at the younger ages. Similar findings were noted in men with the exception that it was less cost-effective to treat men at the age of 50 years for any given fracture probability, mainly due to the exclusion of tibial fractures as being osteoporotic in men. At the age of 60 years and more there was little difference in cost-effectiveness ratio between men and women at any given 10-year probability.

The threshold probability of hip fracture (10-year risk) at which intervention (35\% RRR) became costeffective is shown in Table 1 and Fig. 2 for the base case. In women, this ranged from 1.17 to $7.40 \%$ depending on age. The lower threshold probability at younger ages reflects the influence of fractures other than the hip and the longer survival of younger women. In men the threshold probabilities were higher than in women up to the age of 60 years due to the exclusion of tibial fractures (which were not considered to be due to osteoporosis). Above the age of 65 years the threshold probabilities below which it was cost-effective to inter-
Fig. 1 Cost-effectiveness of an intervention costing $\$ 500$ per annum with an efficacy of $35 \%$, according to age and hip fracture probability. The threshold for cost-effectiveness is set at $\$ 45,000$ per

QALY gained (horizontal line).

Note the logarithmic scale

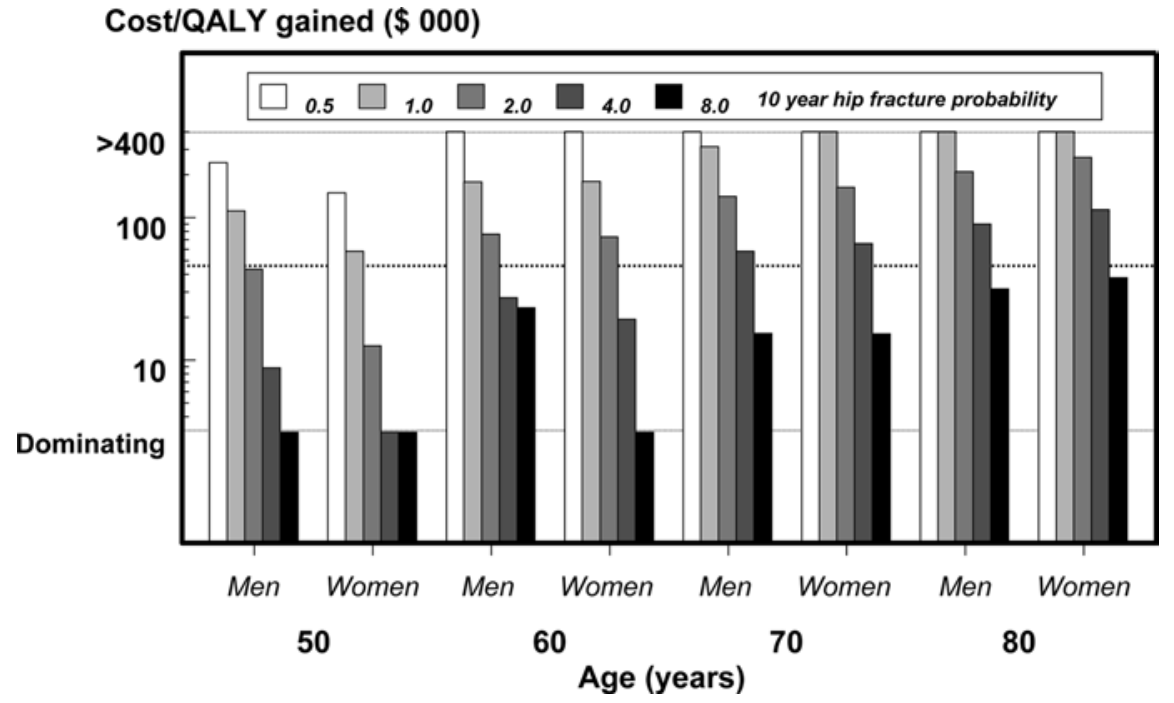


Table 1 Threshold 10-year hip fracture probability at which intervention became cost-effective

\begin{tabular}{|c|c|c|c|c|}
\hline \multirow[t]{2}{*}{$\begin{array}{l}\text { Age } \\
\text { (years) }\end{array}$} & \multicolumn{2}{|c|}{$\begin{array}{l}\text { Hip fracture proba- } \\
\text { bility ( } \% \text { at } 10 \text { years) }\end{array}$} & \multicolumn{2}{|c|}{$\begin{array}{l}\text { Hip fracture proba- } \\
\text { bility }(\% \text { at } 10 \text { years })^{\mathrm{a}}\end{array}$} \\
\hline & Men & Women & Men & Women \\
\hline 50 & 1.98 & 1.17 & 0.41 & 0.55 \\
\hline 55 & 2.36 & 1.80 & 0.68 & 1.16 \\
\hline 60 & 2.96 & 2.73 & 1.17 & 2.35 \\
\hline 65 & 3.72 & 3.98 & 2.02 & 4.54 \\
\hline 70 & 4.74 & 5.11 & 3.22 & 7.67 \\
\hline 75 & 5.42 & 6.08 & 4.46 & 12.24 \\
\hline 80 & 6.46 & 7.40 & 6.23 & 18.38 \\
\hline 85 & 6.31 & 7.23 & 7.25 & 21.90 \\
\hline 90 & 6.16 & 6.62 & 8.03 & 22.00 \\
\hline
\end{tabular}

${ }^{a}$ Average probability in the general population for age and sex

vene were somewhat lower in men than in women, due to the higher mortality in men.

In women it was cost-effective to treat at average risk for age from the age of 65 years whereas in men it was cost-effective to treat from the age of 85 years (see Table 1).

The impact of averting hip fracture alone, hip plus spine plus forearm fracture, or all osteoporotic fractures is shown in Table 2 for a male aged 65 years. When therapy was assumed to decrease hip fracture only, it was not cost-effective to intervene unless the 10-year hip fracture probability exceeded about $10 \%$. Where treatment had effects on hip, spine, and forearm fractures, the threshold probability was approximately $7 \%$. Where all osteoporotic fractures were assumed to decrease with intervention (i.e., the base case), it was cost-effective to intervene with a hip fracture probability of $3.4 \%$.

Effects on hip fracture had a greater quantitative impact than effects on spine fracture. For example, in men aged 75 years with a twofold increase in risk of hip fracture, the cost-effectiveness ratio was $\$ 59,000$ where
Table 2 Cost-effectiveness of intervention in men aged 65 years according to the type of fracture averted

\begin{tabular}{lllcl}
\hline RR & $\begin{array}{l}\text { 10-year } \\
\text { hip fracture } \\
\text { probability } \\
(\%)\end{array}$ & Hip & $\begin{array}{l}\text { Cost/QALY gained (\$000) spine, } \\
\text { and forearm }\end{array}$ & $\begin{array}{l}\text { All osteoporotic } \\
\text { fractures }\end{array}$ \\
\cline { 3 - 5 } & 1.7 & 378 & 221 & 105 \\
1 & 3.4 & 231 & 104 & 39 \\
2 & 5.0 & 113 & 65 & 21 \\
3 & 6.6 & 80 & 46 & 10 \\
4 & 8.1 & 60 & 34 & 3.7 \\
5 & 9.7 & 47 & 27 & -0.5 \\
6 & & & &
\end{tabular}

no effects on vertebral fracture were assumed (Fig. 3). In contrast, in men of the same age and a twofold increase in vertebral fracture risk, the cost-effectiveness ratio was $\$ 87,000$ where no effect on hip fracture was assumed. Where effects on both fracture types were assumed, costeffectiveness improved $(\$ 47,500)$.

The impact of including costs of added years of life is shown in Table 3. Their inclusion increased the costeffectiveness ratio, an effect that increased with advancing age. At the age of 50 years their inclusion decreased the threshold probability at which treatment became cost-effective. By contrast above the age of 75 years, the threshold probability was higher than when the costs of added years was excluded (Table 3 ).

Further one-way sensitivity analyses were undertaken for women aged 60 years to compare with a base-case hip fracture probability at the threshold of cost-effectiveness. Using no discount rate for benefits, the hip fracture probability threshold improved by $15 \%$ (Table 4) since costs were largely confined to the treatment period, whereas benefits continued to accrue after the intervention stopped. For the same reason, the probability threshold improved by $29 \%$ when the offset time was assumed to be 10 rather than 5 years. Conversely, reducing the offset time, adversely affected the
Fig. 2 Intervention thresholds in men and women expressed as 10-year hip fracture probability according to age (solid lines) and average 10 -year hip fracture probability (bars). Note the logarithmic scale
10 year hip fracture probability (\%)

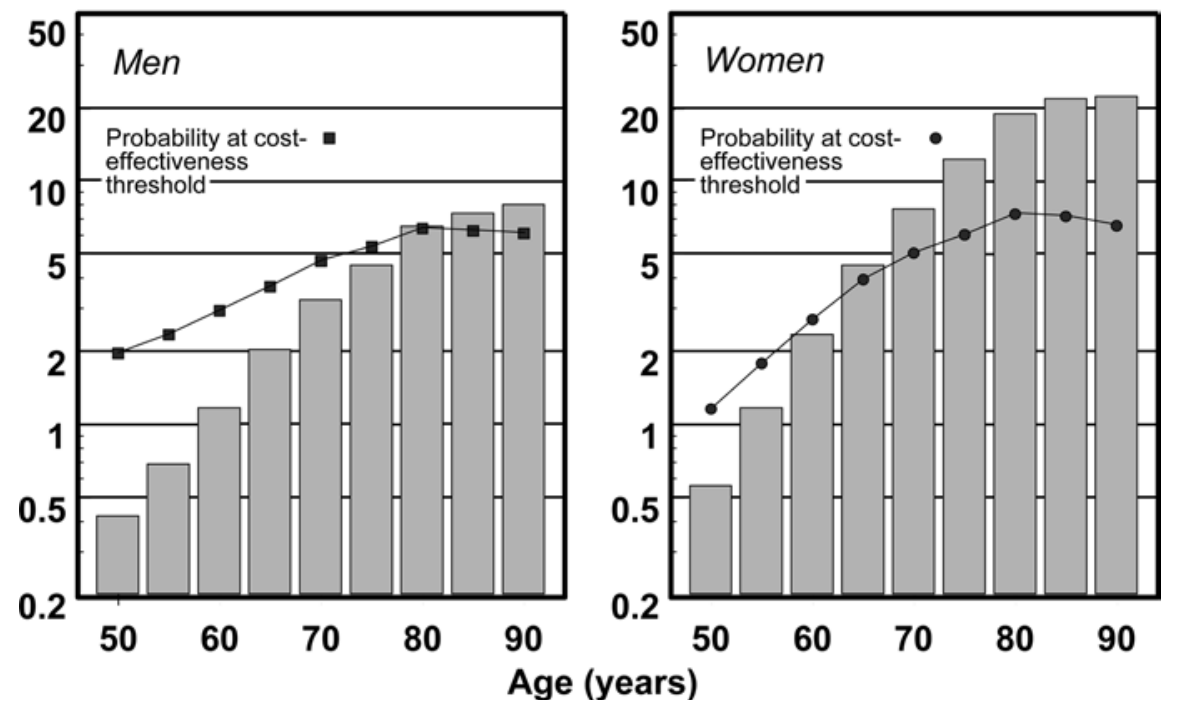


Fig. 3 Cost-effectiveness (\$000/QALY gained) of treatment in men aged 75 years according to relative risk (RR). Treatment is variously assumed to have an effect only on hip fracture risk, vertebral fracture risk, or both

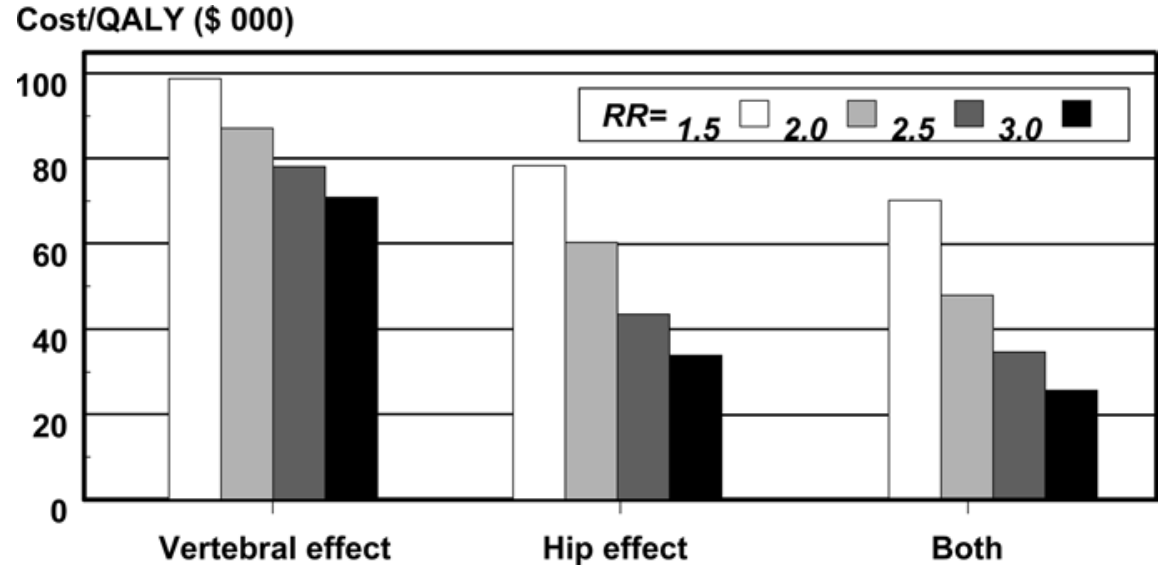

Table 3 Relative risk of hip fracture and 10-year hip fracture probability at which intervention became cost-effective when including costs of added years of life

\begin{tabular}{cccccc}
\hline Age (years) & \multicolumn{2}{l}{ Men } & & \multicolumn{2}{l}{ Women } \\
\cline { 2 - 3 } \cline { 5 - 6 } & RR & $\begin{array}{l}\text { 10-year } \\
\text { probability (\%) }\end{array}$ & & RR & $\begin{array}{l}\text { 10-year } \\
\text { probability (\%) }\end{array}$ \\
\hline 50 & 4.00 & 1.57 & & 1.73 & 0.94 \\
55 & 2.90 & 1.91 & & 1.28 & 1.47 \\
60 & 2.25 & 2.56 & & 0.98 & 2.31 \\
65 & 1.75 & 3.44 & & 0.76 & 3.50 \\
70 & 1.47 & 4.59 & & 0.60 & 4.78 \\
75 & 1.27 & 5.58 & & 0.47 & 6.11 \\
80 & 1.16 & 7.15 & & 0.39 & 7.94 \\
85 & 1.04 & 7.52 & & 0.32 & 6.90 \\
90 & 0.92 & 7.44 & 0.28 & 7.67 \\
\hline
\end{tabular}

Table 4 Sensitivity analysis of 10-year hip fracture probability around a base-case assumption of a 60 -year-old women with a hip fracture probability at the threshold for cost-effectiveness

\begin{tabular}{|c|c|c|c|}
\hline & & $\begin{array}{l}\text { 10-year } \\
\text { probability }(\%)\end{array}$ & Variance $(\%)$ \\
\hline \multirow[t]{3}{*}{ Discounted benefits } & $0 \%$ & 2.29 & -15 \\
\hline & $3 \%{ }^{\mathrm{a}}$ & 2.73 & 0 \\
\hline & $6 \%$ & 3.13 & +15 \\
\hline \multirow[t]{3}{*}{ Offset time } & 0 years & 4.05 & +48 \\
\hline & 5 years $^{\mathrm{a}}$ & 2.73 & 0 \\
\hline & 10 years & 1.95 & -29 \\
\hline \multirow[t]{3}{*}{$\mathrm{RR}$ of fracture } & 1.00 & 2.35 & -14 \\
\hline & $1.17^{\mathrm{a}}$ & 2.73 & 0 \\
\hline & 1.50 & 3.46 & +47 \\
\hline \multirow[t]{4}{*}{ Duration of treatment } & 3 years & 2.38 & -13 \\
\hline & 5 years $^{\mathrm{a}}$ & 2.73 & 0 \\
\hline & 10 years & 2.87 & +5 \\
\hline & 15 years & 2.74 & 0 \\
\hline \multirow[t]{4}{*}{ Efficacy of treatment } & 10 RRR\% & 14.0 & +412 \\
\hline & 20 RRR \% & 5.49 & +101 \\
\hline & $35 \mathrm{RRR} \%{ }^{\mathrm{a}}$ & 2.73 & 0 \\
\hline & 50 RRR\% & 1.85 & -32 \\
\hline \multirow[t]{4}{*}{ Cost of treatment } & $\$ 200$ & 0.99 & -64 \\
\hline & $\$ 300$ & 1.53 & -44 \\
\hline & $\$ 400$ & 2.11 & -23 \\
\hline & $\$ 500^{\mathrm{a}}$ & 2.73 & 0 \\
\hline
\end{tabular}

${ }^{\mathrm{a}}$ Base case probability threshold. Alterations in the duration of treatment had modest effects on cost-effectiveness. Sensitive variables affecting threshold probabilities were the assumed efficacy and cost of intervention.

\section{Discussion}

In this paper we used a simulation model to investigate the cost-effectiveness of a 5-year treatment to prevent osteoporotic fractures in men and women. Major determinants of cost-effectiveness included the age of the individual, the cost of intervention, and the fracture probability. Our analysis shows that it is possible to offer cost-effective intervention even for men and women at moderate risk. For example, for agents of intermediate effectiveness $(35 \%)$ it was cost-effective to treat men aged 85 years and women aged 65 years at average risk with the most expensive intervention, assuming that intervention could be shown to be effective in such a population. Previous estimates examining the costeffectiveness of interventions on the basis of hip fracture alone suggest that intervention in women of average risk at the age of 80 years is cost-effective [51] consistent with the present analysis. Intervention thresholds determined on hip fracture probability alone would neglect the many other fractures, particularly in younger age groups where the frequency of fractures at other sites is much higher than in the elderly $[8,52]$. Even in the elderly, hip fractures represent fewer than $50 \%$ of fractures in men and women aged 80 years or more $[8,52,53]$. Thus, the inclusion of additional fractures due to osteoporosis decreases the threshold substantially as also shown in our sensitivity analysis (see Table 2).

In an earlier paper we published intervention thresholds for women [10], but this has now been updated largely because of the awareness that the morbidity of vertebral fracture is substantially higher than previously assumed [17]. The impact of this revision is to decrease the threshold of risk at which intervention becomes cost-effective, particularly in younger individuals in whom vertebral fractures are more common than hip 
Table 5 The percentage of men and women at the ages shown who would be identified to have a risk that exceeds the intervention threshold according to the gradient of fracture risk / SD, of the assessment algorithm specified

\begin{tabular}{|c|c|c|c|c|}
\hline \multirow[t]{3}{*}{ Age (years) } & \multicolumn{4}{|c|}{ Proportion of population identified $(\%)$} \\
\hline & \multicolumn{2}{|c|}{$\begin{array}{l}\text { Gradient of } \\
\text { risk }=2.6 / \mathrm{SD}\end{array}$} & \multicolumn{2}{|c|}{$\begin{array}{l}\text { Gradient of } \\
\text { risk }=4.0 / \mathrm{SD}\end{array}$} \\
\hline & Men & Women & Men & Women \\
\hline 50 & 1.4 & 9.7 & 3.1 & 10.4 \\
\hline 55 & 3.4 & 16.9 & 5.2 & 15.3 \\
\hline 60 & 6.8 & 26.0 & 8.2 & 21.0 \\
\hline 65 & 12.5 & 37.0 & 12.4 & 27.7 \\
\hline 70 & 18.0 & 49.6 & 16.0 & 35.5 \\
\hline 75 & 24.4 & 62.9 & 20.0 & 44.6 \\
\hline 80 & 30.2 & 72.6 & 23.5 & 52.0 \\
\hline 85 & 37.5 & 80.7 & 28.0 & 59.2 \\
\hline 90 & 43.0 & 84.3 & 31.4 & 62.9 \\
\hline
\end{tabular}

fracture, but the effect is relatively small. From our previous estimates, intervention thresholds, expressed as 10-year hip fracture probabilities, were 1.37, 2.14, 3.18, and $4.14 \%$ at the ages of $50,55,60$, and 65 , respectively. The current estimates (see Table 1) are approximately $15 \%$ lower in women.

The impact of adopting these thresholds depends upon the accuracy with which individuals whose level of risk is at or higher than the threshold can be identified. For BMD measured at the hip, risk increases approximately 2.6-fold for each SD decrease in BMD [54]. Gradients of risk can be improved by the consideration of other independent risk factors [2]. The effect of these considerations on screening strategies is shown in Table 5. At the age of 50 years, approximately $10 \%$ of Swedish women would be identified to be at high risk, a proportion that increases with age, but decreases with higher gradients of risk. In countries with a lower hip fracture probability, the proportion detected would be markedly lower.

To our knowledge the present study is the first to characterize intervention thresholds in men. As expected, these are broadly similar to those found in women, at least from the age of 60 years or more (see Table 1). For men aged 50 or 55 years, intervention thresholds are higher in men than in women. This is explained by the exclusion of tibial fractures since there is little evidence that these can be considered to be osteoporotic in men [8].

The threshold of cost-effectiveness we used was $\$ 45,000$ (£30,000) per QALY gained, consistent with the threshold that has been recommended by NICE in the United Kingdom [32]. The use of a lower threshold as undertaken previously by ourselves and others [9, $51,55]$ would not markedly alter our overall conclusions (see Fig. 1). In a sensitivity analysis we included cost of added years since their inclusion is recommended when taking a societal perspective $[55,56,57]$. The effect of adding these costs is to decrease the fracture probability at which treatment becomes cost-effective at the age of 50 years (see Table 3 ). In the elderly the reverse pertains - namely, that the threshold probability is lower when costs of added years are excluded. Thus, the effect of not adding future costs biases cost-effectiveness in favor of interventions directed at the elderly, and conversely discriminates against the young. For this reason their exclusion disenfranchises the younger population in whom many osteoporotic fractures occur.

The wide range of intervention costs and efficacy poses problems in setting intervention thresholds since changes in the assumptions for both have marked effects on cost-effectiveness. The most conservative scenario is the most expensive intervention and the lowest efficacy. Conversely, the most exuberant would be to choose the level of risk at which the cheapest intervention had the greatest effectiveness. From a societal perspective a basket of treatments are used with a range of efficacy and costs. For the base case, we assumed (as previously published [10]) an average effectiveness of $35 \%$ on all osteoporotic fractures but the highest cost of intervention $(\$ 500)$.

An important finding from the present study is that the threshold of hip fracture probability at which treatment becomes cost-effective is lower with decreasing age (see Table 1). Indeed, for intervention at the age of 50 years a 10 -year probability that exceeds $1.2 \%$ is costeffective in women. By contrast, for those aged 80 years, treatment became cost-effective with a hip fracture probability of $7.4 \%$. This appears to be paradoxical, but arises because it is assumed that intervention decreases the risk of all osteoporotic fractures. In younger women, proportionately more fractures occur at sites other than the hip. Thus, for a given hip fracture probability, more fractures at sites other than the hip are averted. At the age of 50 years, women have a hip fracture probability of $1.2 \%$ which is twice the average hip fracture probability of the general population, but at the age of 80 years, a probability of $7.4 \%$ is lower than the average hip fracture probability for that age (see Table 1). In a practical sense one would offer cost-effective treatment to a 50-year-old woman only where her risk of hip fracture were double that of the general population, but offer the same intervention for the same cost-effectiveness to an 80-year-old woman at average risk. Thus, the effect of age to increase the hip fracture probability at which treatments become cost-effective should not be misconstrued to infer that the younger the age, the more cost-effective treatments become. Indeed, the converse is true.

For women aged 70 years or more, it is, using the base case, cost-effective to treat women at the average population risk (see Fig. 2). For example, it is costeffective to treat women at the age of 70 years with a 10 -year hip fracture probability of $5.1 \%$, whereas the population probability at this age is $7.7 \%$ (see Table 1 ). It is, however, not entirely certain whether the intervention threshold in the elderly should be below the average hip fracture probability for age and sex. 
The reason is that most trials of intervention have targeted men and women with low bone mineral density, with a $T$-score for BMD commonly $<-2.0$ or $<-2.5 \mathrm{SD}$, so that there is less experience of treating individuals with higher values for BMD. Recent studies suggest that efficacy of interventions on vertebral fracture risk is not markedly affected by baseline BMD [58, $59,60]$. For nonvertebral fractures the information base is less but would suggest that antifracture efficacy with bisphosphonates is less marked in individuals with the higher values for BMD [61, 62]. On the other hand, hormone replacement treatment has also been shown to decrease fracture risk when targeted to the general population [35]. Until these uncertainties are resolved it would seem unwise to recommend intervention in individuals whose risk is not increased above that of the population of the same age and sex.

Our conclusions are based on a number of assumptions. A key assumption used in the model concerns the efficacy of treatment. We assumed that if hip fracture risk decreases by a given proportion as a result of treatment, then a comparable effect would be seen for other osteoporotic fractures. This assumption may not be warranted, and for this reason we chose intermediate levels of efficacy. A further important assumption concerning the effectiveness of an intervention is the duration that an effect persists after stopping treatment [25]. There is a great deal of uncertainty over the offset time of many treatments. Relatively rapid offset times of a few years have been observed with calcium, calcitonins, and vitamin D metabolites. Longer offset times are described with the bisphosphonates, estrogens, and tamoxifen, and more recently with parathyroid hormone $[25,63]$. Our assumption of a 5-year offset time is therefore conservative, and longer offset times have been shown to improve markedly cost-effectiveness [25] as shown in the present study. A further consideration is that we modeled a fixed treatment time of 5 years, but altering the duration of intervention has modest effects on costs and effectiveness [34] (see Table 4).

A further uncertainty arises from our use of utilityweighted fracture risks. This approach weights the incidence of different osteoporotic fractures by their disutility. Thus, a single hip fracture in women aged 50 years is equivalent to approximately two vertebral or four humeral fractures in terms of the morbidity caused [17]. This approach avoids the numerous transition states required in a Markov model for the multiple outcomes. The approach also assumes, however, that direct costs of different fractures are proportional to their disutility. The assumption appears to be reasonable, at least as judged by hospital costs (see "Methods"). A further assumption is that deaths arising from fractures are proportional to their disutility. The assumption has not been tested, though it is of relevance that high mortality risks are reported for clinically overt vertebral fractures $[64,65,66,67]$ and other long bone fractures [65] with the exception of those at the distal forearm $[64,65,66]$. The proportion of deaths that are causally related to hip fractures is unknown but is estimated to be approximately $25 \%$ - similar to estimates for vertebral fracture $[68,69]$. Since not all deaths are likely to be causally related we modeled only those deaths occurring in the 1 st year as being potentially reversible with treatment.

It is also important to recognize that our model was populated with information available from Sweden. There is a great deal of heterogeneity in fracture probability around the world $[70,71,72,73]$ as well as in the costs of fracture and costs of intervention. For countries with low hip fracture rates, as found in developing countries, the relative risk at which intervention is costeffective will be higher, though the absolute risk at which intervention is cost-effective would not change assuming comparable costs. Thus, in countries with fracture rates lower than Sweden, a lower proportion of the population would be identified for treatment. Intervention thresholds would, however, change with differences in costs, particularly fracture costs, which in most countries are poorly documented. Notwithstanding, the selection of an intervention threshold to cover the most expensive Swedish treatment with intermediate efficacy may provide some buffer for these variations in costs.

A further important variable in other health care settings is willingness to pay for treatment. The gross domestic product (GDP) varies markedly in different regions of the world. In Sweden the GDP/capita is estimated at $\$ 25,400$ in 2002 , but is only $\$ 7,000$ in Turkey. Thus, for the same fracture risk and the same costs, treatment will be less affordable (at least to health services) in Turkey than in Sweden. On the other hand, individuals in Turkey, rather than society as a whole, may be willing to pay "Swedish prices" for health care. For all these reasons it will be important to define intervention thresholds on a country-by-country basis that takes into account the setting for service provision and willingness to pay, as well as considerations of absolute costs.

In this paper we have modeled only the effects of osteoporotic fractures. The impact of interventions that have generalized extraskeletal benefits and risks would markedly alter cost-effective intervention thresholds [46]. The obvious examples are hormone replacement treatment and the selective estrogen receptor modulators. Both appear to affect breast cancer, though in different directions [74, 75], and both decrease markers of cardiovascular morbidity $[74,75,76]$, though no favorable effects of hormone replacement on cardiovascular events have been shown [35].

Within these limitations a 10 -year probability of hip fracture that varies according to age provides a useable intervention threshold that can be considered in the development of assessment and treatment guidelines in osteoporosis.

Acknowledgements We are grateful to the International Osteoporosis Foundation, Pfizer, Alliance for Better Bone Health, IGEA, Lilly Research Centre, Hologic, Novartis, Wyeth, and Roche for their unrestricted support of these studies. 


\section{References}

1. Kanis JA, Gluer C-C, for the Committee of Scientific Advisors, International Osteoporosis Foundation (2000) An update on the diagnosis and assessment of osteoporosis with densitometry. Osteoporos Int 11:192-202

2. Kanis JA (2002) Diagnosis of osteoporosis and assessment of fracture risk. Lancet 359:1929-1936

3. Anonymous (2001) Statin therapy: what now? Drug Ther Bull 39:17-21

4. Ramsay LE, Haq IU, Jackson PR, Yeo WW (1996) The Sheffield table for primary prevention of coronary heart disease: corrected. Lancet 348:1251-1252

5. Ramsay LE, Haq IU, Jackson PR, Yeo WW, Pickin DM, Payne JN (1996) Targeting lipid-lowering drug therapy for primary prevention of coronary artery disease: an updated Sheffield table. Lancet 348:387-388

6. Wood D, DeBacker G, Faergemon O, Graham I, Mancia G, Pyoralle K (1998) Prevention of coronary heart disease in clinical practice: recommendations of the second joint task force of European and other societies on coronary prevention. Artherosclerosis 140:199-270

7. Johannesson M (2001) At what coronary risk level is it costeffective to initiate cholesterol lowering drug treatment in primary prevention. Eur Heart J 22:919-925

8. Kanis JA, Oden A, Johnell O, Jonsson B, De Laet C, Dawson A (2001) The burden of osteoporotic fractures: a method for setting intervention thresholds. Osteoporos Int 12:417-427

9. National Osteoporosis Foundation (1998) Osteoporosis: review of the evidence for prevention, diagnosis and treatment and cost-effectiveness analysis. Osteoporos Int 8[Suppl 4]:1-88

10. Kanis JA, Johnell O, Oden A, De Laet C, Oglesby A, Jonsson B (2002) Intervention thresholds for osteoporosis. Bone 31; 26-31

11. Merlino LA, Bagchi I, Taylor TN, Utrie P, Chrischilles E, Sumner W, Mudano A, Saag KG (2001) Preferences for fractures and other glucocorticoid-associated adverse events among rheumatoid arthritis patients. Med Decis Making 21:122-132

12. Gabriel SE, Kneeland T, Melton LJ et al (1999) Health related quality of life in economic evaluations for osteoporosis: whose values should we use? Med Decis Making 19:141-148

13. Zethraeus N, Borgstrom F, Johnell O, Kanis JA, Jonsson B (2002) Costs and quality of life associated with osteoporosis related fractures: results of a Swedish survey. Working Paper Series in Economics and Finance, Report 512. Stockholm School of Health Economics, Stockholm

14. Tosteson ANA, Gabriel SE, Grove MR, Moncur MM, Kneeland TS, Melton LJ (2001) Impact of hip and vertebral fractures on quality adjusted life years. Osteoporos Int 12:10421049

15. Nevitt MC, Ettinger B, Black DM, Stone K, Jamal SA, Ensrud K, Segal M, Genant HK, Cummings SR (1998) The association of radiographically detected vertebral fractures with back pain and function: a prospective study. Ann Intern Med 128:793800

16. Nevitt, MC, Thompson, DE, Black, DM, Rubin, SR, Ensrud, $\mathrm{K}$, Yates, AJ, Cummings, SR for the fracture intervention trial research group (2000) Effect of alendronate on limited-activity days and bed-disability days caused by back pain in postmenopausal women with existing vertebral fractures. Arch Intern Med 160:77-85

17. Kanis JA, Johnell O, Oden A, Borgstrom F, Zethraeus N, De Laet C, Jonsson B (2003) The risk and burden of vertebral fracture in Sweden. Osteoporos Int (in press)

18. O'Neill TW, Lunt M, Silman AJ, Felsenberg D, Benevolenskaya LI, Bhalla A, Cannata JB, Cooper C, Crabtree N, Dequeker J, Hoszowski J, Jajic K, Kanis JA, Kragl G, Lopez Vaz A, Lorenc R, Lyritis G, Masaryk P, Miazgowski T, Parisi G, Pols HAP, Poor G, Reid DM, Scheidt-Nave C, Stepan G, Todd C, Weber K, Woolf AP, Reeve J (2002) The relationship between bone density and incident vertebral fracture in men and women. J Bone Miner Res 17:2214-2221
19. De Laet CEDH, van Hout BA, Burger $\mathrm{H}$, Weal AEAM, Hofman A, Pols HAP (1998) Hip fracture prediction in elderly men and women: validation in the Rotterdam Study. J Bone Miner Res 13:1587-1593

20. De Laet CEDH, van der Klift M, Hofman A, Pols HA (2002) Osteoporosis in men and women: a story about bone mineral density thresholds and hip fracture risk. J Bone Miner Res 17:2231-2236

21. Kanis JA, Johnell O, Oden A, De Laet C, Mellstrom D (2001) Diagnosis of osteoporosis and fracture threshold in men. Calcif Tissue Int 69:218-221

22. Johnell O, De Laet C, Johansson H, Melton LJ, Eisman J, Reeve J, Tenenhouse A, McCloskey EV, Kanis JA (2002) Oral corticosteroids increase fracture risk independently of BMD. Osteoporos Int 13[Suppl 1]:S14

23. De Laet C, Johansson H, Johnell O, Kanis JA, McCloskey EV, Mellstrom D, Melton LJ, Oden A, Delmas P, Geusens P, Oglesby A, Eisman J, Pols H, Reeve J, Silman A, Tenenhouse A (2003) A meta-analysis of body mass index (BMI) as a predictor of fracture risk. J Bone Miner Res (in press)

24. Jonsson B, Christiansen C, Johnell O, Hedbrandt J (1995) Cost-effectiveness of fracture prevention in established osteoporosis. Osteoporos Int 5:136-142

25. Jonsson B, Kanis JA, Dawson A, Oden A, Johnell O (1999) Effect and offset of effect of treatments for hip fracture on health outcomes. Osteoporos Int 10:193-199

26. Zethraeus N, Stromberg L, Jonsson B, Svensson O, Ohlen G (1997) The cost of a hip fracture. Acta Orthop Scand 68:13-17

27. Gabriel SE, Tosteson ANA, Leibson CL, Crowson CS, Pond GR, Hammond CS, Melton LJ (2002) Direct medical costs attributable to osteoporotic fractures. Osteoporos Int 13:323330

28. Melton LJ, Gabriel SE, Crowson CS, Tosteson ANA, Johnell O, Kanis JA (2003) Cost equivalence of different osteoporotic fractures. Osteoporos Int 14:383-388

29. Burge R, Puelo E, Gehlbach S, Worley D, Klar J (2002) Inpatient hospital and post-acute care for vertebral fractures in women. Value Health 5:301-311

30. Parker MJ, Anand JK (1991) What is the true mortality after hip fracture. Public Health 105:443-446

31. Kanis JA, Oden A, Johnell O, De Laet C, Jonsson B (2004) Excess mortality after hospitalisation for vertebral fracture. Osteoporos Int (in press)

32. Raftery J (2001) NICE: faster access to modern treatments? analysis of guidance on health technologies. BMJ 323:13001303

33. Almbrand B, Johannesson M, Sjostrand B, Malmberg K, Ryden L (2000) Cost effectiveness of intense insulin treatment after acute myocardial infarction in patients with diabetes mellitus. Eur Heart J 21:733-739

34. Kanis JA, Brazier JE, Stevenson M, Calvert WW, Lloyd Jones M (2002) Treatment of established osteoporosis: a systematic review and cost utility analysis. Health Technology Assessment 6(29): $1-146$

35. Writing Group for the Women's Health Initiative (2002) Risks and benefits of estrogen plus proestin in healthy postmenopausal women: principal results from the Women's Health Initiative Randomized Controlled Trial. JAMA 288:321-333

36. Chapuy MC, Arlot ME, Delmas PD, Meunier PJ (1994) Effect of cholecalciferol treatment for 3 years on hip fractures in elderly women. BMJ 308:1081-1082

37. Black DM, Cummings SR, Karpf DB, Cauley JA, Thompson $\mathrm{DE}$, Nevitt MC et al, for the Fracture Intervention Trial Research Group (1996) Randomised trial of effect of alendronate on risk of fracture in women with existing vertebral fractures. Lancet 348:1535-1541

38. Liberman UA, Weiss SR, Broll J, Minne HW, Quan H, Bell $\mathrm{NH}$, for the Alendronate Phase III Treatment Study Group (1995) Effect of oral alendronate on bone mineral density and the incidence of fractures in postmenopausal osteoporosis. N Engl J Med 333:1437-1443 
39. Reginster JY, Minne HW, Sorensen OH, Hooper M, Roux C, Brandi ML et al, on behalf of the Vertebral Efficacy with Risedronate Therapy (VERT) Study Group (2000) Randomised trial of the effects of risedronate on vertebral fractures in women with established osteoporosis. Osteoporos Int 11:83-91

40. The Osteoporosis Methodology Group and the Osteoporosis Research Advisory Group (2002) Meta-analysis of therapies for postmenopausal osteoporosis. Endocr Rev 23:496-507

41. Harris ST, Watts NB, Genant HK, McKeever CD, Hangartner $\mathrm{T}$, Keller $\mathrm{M}$ et al, for the Vertebral Efficacy with Risedronate Therapy (VERT) Study Group (1999) Effects of risedronate treatment on vertebral and non-vertebral fractures in women with postmenopausal osteoporosis. JAMA 282:1344-1352

42. Kanis JA, Johnell O, Gullberg B, Allander E, Dilsen G, Gennari C, Lopez Vaz AA, Lyritis G, Mazzuoli G, Miravet L, Passeri M, Perez Cano R, Rapado A, Ribot C (1992) Evidence for the efficacy of bone active drugs in the prevention of hip fracture. BMJ 305:1124-1128

43. Keil DP, Felson DT, Anderson JJ (1987) Hip fracture and the use of estrogens in postmenopausal women: the Framingham Study. N Engl J Med 317:1169-1174

44. Weiss NS, Carol PH, Ure L, Ballard JH, Williams AR, Darling JR (1980) Decreased risk of fractures of the hip and lower forearm with postmenopausal use of oestrogen. N Engl J Med 303:1195-1198

45. Torgerson DJ, Kanis JA (1995) The cost effectiveness of preventing hip fractures using vitamin D and calcium. Quart J Med 88:135-139

46. Zethraeus N, Johannesson M, Jonsson B (1998) A computer model to analyse the cost-effectiveness of hormone replacement therapy. EFI Research Paper, No. 6578, January. Stockholm School of Economics, Stockholm

47. Kanis JA, Johnell O, Oden A, Sernbo I, Redlund-Johnell I, Dawson A, De Laet C, Jonsson B (2000) Long-term risk of osteoporotic fracture in Malmo. Osteoporos Int 11:699-674

48. Oden A, Dawson A, Dere W, Johnell O, Jonsson B, Kanis JA (1998) Lifetime risk of hip fracture is underestimated. Osteoporos Int 8:599-603

49. Klotzbuecher CM, Ross PD, Landsman PB, Abbott TA, Berger M (2000) Patients with prior fractures have an increased risk of future fractures: a summary of the literature and statistical synthesis. J Bone Miner Res 15:721-739

50. Zethraeus N, Gerdtham UG (1998) Estimating the costs of hip fracture and potential savings. Int $\mathbf{J}$ Technol Assess Health Care 14:255-267

51. Kanis JA, Dawson A, Oden A, Johnell O, De Laet C, Jonsson B (2001) Cost effectiveness of preventing hip fractures in the general female population. Osteoporos Int 12:356-361

52. Melton LJ, Crowson CS, O'Fallon WM (1999) Fracture incidence in Olmsted County, Minnesota: comparison of urban with rural rates and changes in urban rates over time. Osteoporos Int 9:29-37

53. Jones G, Nguyen PN, Sambroske PN, Kelly PJ, Gilberg C, Eisman JA (1994) symptomatic fracture incidence in elderly men and women. The Dubbo Osteoporosis Epidemiology Study (DOES). Osteoporos Int 4:277-282

54. Marshall D, Johnell O, Wedel H (1996) Meta-analysis of how well measures of bone mineral density predict occurrence of osteoporotic fractures. Lancet 312:1254-1259

55. Johannesson M, Meltzer D, O'Connor R (1997) Incorporating future costs in medical cost-effectiveness analysis. Med Decis Making 7:382-389

56. Meltzer D (1997) Accounting for future costs in medical costeffectiveness analysis. J Health Econ 16:33-64

57. Kanis JA, Jonsson B (2002) Economic evaluation of interventions for osteoporosis. Osteoporos Int 13; 765-767

58. Kanis JA, Johnell O, Black DM, Downs RW, Sarkar S, Fuerst $\mathrm{T}$, Secrest RJ, Pavo I (2003) Effect of raloxifene on the risk of new vertebral fracture in postmenopausal women with osteopenia or osteoporosis. Bone (in press)
59. Black DM, Thompson D, Quandt S, Palermo L, Ensrud K, Johnell O (2002) Alendronate reduces the risk of vertebral fracture in women with BMD $T$-scores above -2.5 : results from the Fracture Intervention Trial (FIT). Osteoporos Int 13[Suppl 1]:S27

60. Marens R, Wang O, Satterwhite J, Mitlak B (2003) The skeletal response to teriparatide is largely independent of age, initial bone mineral density and prevalent vertebral fractures in postmenopausal women with osteoporosis. J Bone Miner Res $18: 18-23$

61. Cummings SR, Black DM, Thompson DE, Applegate WB, Barret-Connor E, Musliner TA, Palermo L, Prieas R, Rubin SM, Scott JC, Vogt T, Wallace R, Yates AJ, LaCrois AZ (1998) Effect of alendronate on risk for fractures in women with low BMD but without vertebral fractures. JAMA 280:2077-2082

62. McClung MR, Geusens P, Miller PD, Zippel H, Bensen WG, Roux C, Adami S, Fogelman I, Diamond T, Eastell R, Meunier PJ, Reginster JY (2001) Effect of risedronate on the risk of hip fracture in elderly women. Hip Intervention Program study Group. N Engl J Med 344:333-340

63. Neer RM, Arnand CD, Zanchetta JR, Prince R, Gaich GA, Reginster JY, Hodsman AB, Eriksen EF, Ishi-Shalom S, Genant HK, Wang O, Mitlak B (2001) Effects of parathyroid hormone (1-34) on fractures and bone mineral density in postmenopausal women with osteoporosis. N Engl J Med 344 1434-1441

64. Cauley JA, Thompson DE, Ensrud KC, Scott JC, Black D (2000) Risk of mortality following clinical fractures. Osteoporos Int 11:556-561

65. Center JR, Nguyen TV, Schneider D, Sambrook PN, Eisman JA (1999) Mortality after all major types of osteoporotic fracture in men and women: and observational study. Lancet 353:878-882

66. Cooper C, Atkinson EJ, Jacobsen SJ, O'Fallon WM, Milton LJ (1993) Population-based study of survival after osteoporotic fractures. Am J Epidemiol 137:1001-1005

67. Kado DM, Browner WS, Palermo L, Nevitt MC, Genant HK, Cummings SR, for the Study of Osteoporotic Fractures Research Group (1999) Vertebral fractures and mortality in older women. Arch Int Med 159:1215-1220

68. Kanis JA, Oden A, Johnell O, De Laet C, Jonsson B, Oglesby AK (2003) The components of excess mortality after hip fracture. Bone 32:468-473

69. Kanis JA, Oden A, Johnell O, De Laet C, Jonsson B (2003) Excess mortality after hospitalization for vertebral fracture. Osteoporos Int (in press)

70. Bacon WE, Maggi S, Looker A, Harris T, Nair CR, Giaconi J, Honkanen R, Ho SC, Peffus KA, Torring O, Gass R, Gonzales N (1996) International comparison of hip fracture rates in 1988 to 1989 . Osteoporos Int 6:69-75

71. Elffors L, Allander E, Kanis JA, Gullberg B, Johnell O, Dequeker J, Dilsen G, Gennari C, Lopes Vaz AA, Lyritis G et al (1994) The variable incidence of hip fracture in Southern Europe: the MEDOS Study. Osteoporos Int 4:253-263

72. Johnell O, Gullberg B, Allander E, Kanis JA (1992) The apparent incidence of hip fracture in Europe: a study of national register sources. Osteoporos Int 2:298-302

73. Kanis JA, Johnell O, De Laet C, Jonsson B, Oden A, Oglesby A (2002) International variations in hip fracture probabilities: implications for risk assessment. J Bone Miner Res 17:12371244

74. Cummings SR, Eckert S, Krueger KA et al (1999) The effect of raloxifene on risk of breast cancer in postmenopausal women: results from the MORE randomized trial. JAMA 281:21892197

75. World Health Organization (1994) Assessment of fracture risk and its application to screening for postmenopausal osteoporosis. WHO Technical Report Series, No. 843. WHO, Geneva

76. Hillner BE, Hollenberg JP, Pauker SG (1986) Postmenopausal estrogens in prevention of osteoporosis: benefit virtually without risk if cardiovascular effects are considered. Am J Med 80:1115-1127 